\title{
Post herpetic neuralgia management: A retrospective analysis
}

\author{
Punam Kapur $^{1}$, Ashok Pathak ${ }^{2, *}$, Niharika Chaudhary ${ }^{3}$, Rahul Sharma ${ }^{4}$, Manjula Suri ${ }^{5}$ \\ ${ }^{1,2}$ Professor, ${ }^{3,4}$ Senior Resident, Dept. of Ophthalmology, Dr Ram Manohar Lohia Hospital, New Delhi, ${ }^{\mathbf{5}}$ Associate Professor, \\ Dept. of Home Economics, Delhi University, New Delhi, India
}

*Corresponding Author:

Email: pathakashok22@yahoo.com

\begin{abstract}
Acute Herpes Zoster (AHZ) occurs due to reactivation of dormant Varicella zoster virus within neurons. It is more common in the elderly diabetics and immuno-compromised patients. Such patients are more likely to develop debilitating neuropathic pain known as post herpetic neuralgia (PHN). Various researchers suggest that early antiviral treatment can prevent development of PHN and reduce it's severity when it does occur. A retrospective study on 45 patients of herpes zoster ophthalmicus treated with oral acyclovir of different strengths with or without systemic steroid were evaluated for post herpetic neuralgia at repeated intervals for one Year in herpes zoster ophthalmicus cases. Our study suggests that a combination of antiviral drugs and steroid may have the best results in the management of PHN.
\end{abstract}

Keywords: Herpes zoster ophthalmicus, Post herpetic neuralgia, Painscore, Treatment.

\section{Introduction}

Herpes zoster presents as a rash of 2-3 weeks duration in immunocompromised patients that is accompanied by moderate to severe pain. ${ }^{1}$ Herpes zoster ophthalmicus occurs when reactivation of the latent virus in the trigeminal ganglia involves the ophthalmic division of the nerve. Herpes zoster affects the trigeminal ganglion in 10-15 percent of patients with ophthalmic division involvement in $89 \%$ of these patients. ${ }^{2,3}$ The virus damages the eye and surrounding structures by secondary perineural and intraneural inflammation of sensory nerves. ${ }^{4}$ Herpes zoster ophthalmicus represents approximately 10 to 25 percent of all cases of Herpes zoster. ${ }^{5}$ Although herpes zoster ophthalmicus most often produces a classic dermal rash, a minority of patients may have only ophthalmic findings, limited mainly to the cornea. Direct ocular involvement is not specifically correlated with age, gender or severity of disease. Serious sequelae include chronic ocular inflammation and vision loss.

In some patients pain does not resolve when the rashes heal but continues for weeks, months or years. The persistent pain is called post herpatic neuralgia. The IHS (International Headache Society) defines post herpetic neuralgia (PHN) as follows:-

1. Pain in the distribution of a nerve or nerve division in the head.

2. Herpetic eruption in the territory of the nerve.

3. Pain precedes eruption of rashes by less than 7 days.

4. Pain lasts longer than 3 months.

The pain is constant deep burning or gnawing and may be provoked by light touch. Paraesthesis, dysaesthesia and electric shock like pain have been reported. No single treatment relieves PHN. In many cases a combination of treatment is required. ${ }^{7}$ Oral antiviral agents are recommenced for seven days in patients with $\mathrm{HZ}$ who are at risk of developing PHN (patients over 50 years old with severe acute pain, severe rash, or significant prodromal symptoms). Despite the combined use of tricyclic antidepressants, anticonvulsants (gabapentin and pregabalin), antiviral drugs and analgesics, PHN is often refractory to pharmacological treatment and prevention strategies. ${ }^{8,9}$

Aim of Study: To compare the effect of acyclovir, steroids and combination therapy in the pain management of post herpetic zoster neuralgia.

\section{Materials and Methods}

A retrospective study comprising cases of Herpes zoster opththalmicus with post herpetic neuralgia treated at the Department of ophthalmology, Dr. RML Hospital, New Delhi was designed based on the patients' records over a period of five years from 20102015 with a minimum follow up period of one year. Patient's age, gender, history of herpetic involvement, pain score, type of management given to the patient and recurrences were also noted. Pain scoring was done based on verbal ratings. Pain scoring was done at the time of presentation, one month, three months, and one year. Numerical ratings were done on a scale of 0-10.

0 : No pain

1-3: Mild pain

4-6: Moderate pain

7-10: Severe pain

\section{Results}

A total of 45 cases of herpes zoster opthalmicus with post herpetic neuralgia presenting in OPD from 2010-2015 were evaluated as described above for a minimum follow up period of one year. Approximately $24.4 \%$ cases in our study were less than 50 years of age. Not much difference was seen in the number of male and female patients. (Table 1) 
$15.5 \%$ of cases presented before the onset of rashes. Maximum number of patients presented with a week of onset of rashes (Table 2).

Patients were treated with acyclovir $200 \mathrm{mg}, 400 \mathrm{mg}$ or $800 \mathrm{mg} 5$ times daily for 1 week depending upon the severity of illness. Steroids were given in some cases in the form of oral prednisolone (40mg) daily and tapered over a period of 3 weeks.

On the basis of treatment given, the patients were grouped as follows:

Group-I: Only acyclovir $200 \mathrm{mg}$, 400mg or $800 \mathrm{mg}$.

Group-II: Only steroids.

Group-III: Combined acyclovir in varying doses of $200 \mathrm{mg}$, $400 \mathrm{mg}$ or $800 \mathrm{mg}$ and oral steroids.

Group-IV: No treatment.

The patients were followed up for a minimum of one year duration. Pain scoring was done at the time of presentation, one month, three months, and one year, Numerical ratings were done on a scale of 0-10.

0 : No pain

1-3: Mild pain

4-6: Moderate pain

7-10: Severe pain

In our study (table no. 3) all patients who recovered from neuralgia as early as three months were those who received acyclovir and oral steroids together. Equivalent results were seen in such cases as regards the varying doses of acyclovir at one year follow up. At $1 \mathrm{yr}$ follow up only one of 15 cases receiving acyclovir alone and one out of 10 cases receiving oral steroids alone were symptom free where as those receiving combination of acyclovir and oral steroids were symptom free in 14 out of 16 cases.

Table 1: Age distribution

\begin{tabular}{|l|c|c|c|c|c|}
\hline S. No. & Age of the patient & No of male patient & $\begin{array}{c}\text { No. of female } \\
\text { patient }\end{array}$ & Total patients & Total percentage \\
\hline 1. & Less than 40yrs & 1 & 1 & 2 & $4.4 \%$ \\
\hline 2. & $40-50 \mathrm{yrs}$ & 6 & 3 & 9 & $20 \%$ \\
\hline 3. & $50-60 \mathrm{yrs}$ & 13 & 9 & 22 & $48.8 \%$ \\
\hline 4. & $60-70 \mathrm{yrs}$ & 3 & 4 & 7 & $5.5 \%$ \\
\hline 5. & more than 70yrs & 2 & 3 & 5 & $11.1 \%$ \\
\hline 6. & Total & 25 & 20 & 45 & \\
\hline
\end{tabular}

Table 2: Time of first presentation

\begin{tabular}{|l|l|c|c|}
\hline S. No. & & No. of patients & Percentage \\
\hline 1. & Before onset of rash & 7 & 15.5 \\
\hline 2. & Onset to 7 days & 19 & 42.1 \\
\hline 3. & 7 days to 1 month & 12 & 26.6 \\
\hline 4. & 1-3 months & 5 & 11.1 \\
\hline 5. & After 3 months & 2 & 4.4 \\
\hline
\end{tabular}

Table 3: Mean pain scores at follow up

\begin{tabular}{|l|c|c|c|c|}
\hline & Initial & 1 month & 3 month & 1 year \\
\hline Group 1 $(\mathrm{n}=15)$ & 8.6 & 5.2 & 2.9 & 1.6 \\
\hline Group 2(n=10) & 6.9 & 3.2 & 2.4 & 1.4 \\
\hline Group 3(n=16) & 7.6 & 3 & 0.5 & 0.18 \\
\hline Group 4(n=4) & 4 & 2.5 & 2 & 1 \\
\hline
\end{tabular}

\section{Discussion}

Theoretical models suggest that reducing pain during the acute phase of herpes zoster may stop the initiation of the mechanisms that cause chronic pain, thus reducing the risk of postherpetic neuralgia. ${ }^{10}$ If the condition develops, treatment focuses on preventing chronic pain syndrome. Several medications have proved effective for postherpetic neuralgia and should be selected based on individual patient characteristics. ${ }^{11-15}$

Multiplicity of drugs like carbamazepine, gabapentin, amitryptline, local capsaicin cream have been tried to treat PHN and it can be refractory to these therapies. Older age, greater acute pain during herpetic and greater rash severity are risk factors for PHN. There is a greater risk of PHN in patients with severe acute infection accompanied by greater neural damage. ${ }^{16}$ Scheie reported successful use of oral steroids in PHN and decreased severity of keratitis, uveitis, glaucoma. ${ }^{17}$ Treatment of Herpes zoster ophthalmicus by acyclovir and other antiviral drugs reduces the severity of infection and limits damage, ${ }^{18}$ but antiviral therapy does not prevent PHN in all patients, ${ }^{19}$ though varying evidences exist showing prompt antiviral treatment can prevent the development of PHN and reduce severity when it does occur. Options include acyclovir and the newer antiviral drugs likely valacyclovir and famciclovir. Their benefits include a reduction in the 
incidence of PHN at 6 months and a faster resolution of the pain symptoms. The early use of acyclovir has also been shown to reduce the incidence and severity of PHN. ${ }^{20}$ The optimum window seems to be within 72 hours of appearance of the $\operatorname{rash}^{21}$ but observational studies suggest even treatment outside 3 days may be of benefit. $^{22}$ This is particularly for patients at high risk of morbidity such as those affected by herpes zoster ophthalmicus and HIV. ${ }^{23}$

The addition of corticosteroids to acyclovir decreases the pain of acute herpes zoster ${ }^{24}$ and speeds lesion healing and return to daily activities. Combination therapy with corticosteroids and antivirals should be considered in older patients with no contraindications. ${ }^{24}$

\section{Conclusion}

Our study shows that a combination of oral steroids and acyclovir may be the best option to prevent PHN in a case of herpes zoster ophthalmicus. Dosage of acyclovir can be titrated according to the severity of herpes zoster. The study does have limitations in the form of small size, subjective assessment of the pain and the study being retrospective. Prospective RCTs with large sample size are needed.

\section{References}

1. Gnann JW, Whitley RJ. Herpes Zoster. N Engl J Med. 2002, 347(5):340-346.

2. Ragozzino MW, Melton LI, Kerland LT. Population based study of Herpes Zoster and its sequelae. Medicine. 1982;61(5):310-316.

3. Dworkin RH, Portenoy RK. Pain and its persistence in Herpes Zoster. Pain. 1996;67(2-3):241-251.

4. Naumann G, Gass JD, Font RL. Histopathology of herpes zoster ophthalmics. Am J Ophthalmol. 1968;65(4):533541.

5. Headache classification committee of international headache society. International classification of headache disorders Ed 2nd Cephalgia, 2004;1:1-1600.

6. Strauss; Shingles; sorrows, slaves land solution JAMP. 1993;269:1836-1839.

7. Liesegang TL. Herpes Zoster virus infection. Cur opinion Ophthal. 2004;15(6):531-536.

8. Dworkin RH, Schmader KE. 'Epidemiology and natural history of Herpes Zoster and post herpetic neuralgia' in Watson CPN. Gershan AA. Herpes Zoster and post herpetic neuralgia $2^{\text {nd }}$ New York; Elsevier pres 2001;3964.

9. Gnann JW, Whitley RJ. Clinical practice. Herpes zoster. N Engl J Med. 2002;347(5)340-346.

10. Watson Postherpetic Neuralgic Clinevid October 2010. Available from http://clinicalevidence.bmj.com/ceweb/conditionjs/ind090 5/0905.

11. Garroway N, Chhabra S, Landis S, SkolnikDCm. Clinical inquiries: what measures relieve postherpetic neuralgia ?" J Fam Pract. 2009;58(7):384d-f.

12. Dubinsky RM, Kabbani H, El-Chami Z, et al, Practice parameter: treatment of postherpetic neuralgia: and evidence-based report of the Quality Standards subcommittee of the American academy of Neurology. Neurology. 2004;63(6):959-965.
13. Hollingshead J, Buhmke RM, Cornblath DR. Tramadol for neuropathic pain. Cochrane Database Syst Rev. 2006;3:CDOO3726.

14. Khaliq W, Alam S, Puri N. Topical lidocaine for the treatment of postherpetic neuralgia. Cochrane Syst Rev. 2007;(2) CDOO4846.

15. Whitley RJ, Weiss HL. Soong SI"Herpes Zoster : risk categories for persistent pain" J. infect dis. 1999;179-9-5.

16. Scheie HC. Herpes zoster ophthalmicus. Trans Ophtholmol Soc. UK 1930;90:899.

17. Jackson JL. Gibbons R, Meyer G. The effect of treating Herpes Zoster with oral acyclovir in preventing post herpetic neuralgia: a meta analysis. Arch intern med. 1997;157;909-12.

18. Dworkin RH, Boon RJ, Griffin DR, Post herpetic neuralgia: impact of famciclovir, age, rash severity and acute pain in herpes zoster patient. J infect Dis. 1998, 178(supp1)10576-80.

19. Chrito PJ, Hobelmann, Maine DN. Post-herpetic neuralgia in older adults: evidence-based approaches of clinical management. Drugs \& Aging. 2007;24(1):1-19.

20. Wood MJ, Shukla S. Flodian A, Crooks RJ "Treatment of acute herpes zoster: effect of early $(<48 \mathrm{~h})$ versus late (48-72) $\mathrm{h}$ therapy with acyclovir and valaciclovir on prolonged pain. $J$ infect Dis. 1998;178 suppl 1LS81-S84.

21. Decroix J, Partsch H, Gonzalez R, et al. Outcome in herpes zoster: an observational study with valaciclovir. $J$ Eur Acad Dermatol Venereol. 2000;14:23-33.

22. Lam FC, Law A, Wykes W. Herpes zoster ophthalmicus. BMJ. 2009;339:2624.

23. Wareham DW; Breuer J. Herpes zoster. BMJ. 2007;334:1211-1215.

24. Coplan PM, Schnader K, Nikas A et al., Development of a measure of burden of pain due $\&$ herpes zoster and post herpetic neuralgia for prevention trials: Adoption of the brief pain inventory. Journal of Pain. 2004;5;344-56.

How to cite this article: Kapur P, Pathak A, Chaudhary N, Sharma R, Suri M. Post herpetic neuralgia management: A retrospective analysis. Ind $\mathrm{J}$ Clin Exp Ophthalmol. 2018;4(3):406-408. 